\title{
Severe quadricuspid aortic valve stenosis after mediastinal irradiation
}

Gianclaudio Mecozzi, MD, ${ }^{a}$ Stefano Pratali, MD, ${ }^{a}$ Aldo Milano, MD, ${ }^{a}$ Carmela Nardi, MD, and Uberto Bortolotti, MD, Pisa, Italy

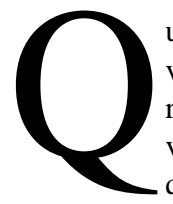

uadricuspid aortic valve is an uncommon cause of valve dysfunction, because it is usually found at necropsy or incidentally recognized at operation for severe aortic regurgitation. ${ }^{1-3}$ Severe aortic stenosis requiring valve replacement involving a quadricuspid aortic valve has not been reported. In the case presented here, stenosis in a quadricuspid aortic valve is likely to have been favored by previous mediastinal irradiation.

\section{Clinical Summary}

A 48-year-old man began having exertional angina 1 year before admission. Risk factors for cardiovascular disease included hypercholesterolemia and smoking. Approximately 30 years previously, he had received mediastinal irradiation for a metastatic seminoma with a total radiation dose of $3000 \mathrm{cCy}$ without further sequelae. A stress test was negative for myocardial ischemia, but a transthoracic 2-dimensional echocardiogram disclosed severe calcific aortic stenosis with a peak transvalvular gradient of $90 \mathrm{~mm} \mathrm{Hg}$ and trivial aortic regurgitation. There was also evidence of left ventricular hypertrophy with preserved function. After recurrent episodes of chest pain, he was admitted for further evaluation and treatment. Physical examination showed a systolic ejection murmur in the aortic area. The electrocardiogram disclosed sinus rhythm and signs of left ventricular hypertrophy, whereas the chest $\mathrm{x}$-ray film showed no abnormalities. Angiography showed occlusion of the right coronary artery and stenosis of a small marginal branch of the left circumflex; fluoroscopy revealed diffuse calcification of the aortic root. At operation in September 2002, calcifications appeared confined to the aortic root. The aortic arch was cannulated, and on moderately hypothermic cardiopulmonary bypass, the heart arrested with cold blood cardioplegic solution infused into the aortic root. A segment of saphenous vein was grafted to the right coronary artery. The aortic valve appeared formed by 3 cusps of equal size and a small accessory cusp between the right and noncoronary cusps; all cusps were fibrotic and grossly calcified (Figure 1). Because of the coarse calcification of the aorta, the aortic valve and root were replaced with a $23-\mathrm{mm}$ cryopreserved aortic homograft with coronary ostia reimplantation. The proximal end of the venous graft was then anastomosed

From the Divisions of Cardiac Surgery ${ }^{\mathrm{a}}$ and Cardiology, ${ }^{\mathrm{b}}$ Cardio Thoracic Department, University of Pisa Medical School, Pisa, Italy.

Received for publication Jan 9, 2003; accepted for publication Jan 22, 2003.

Address for reprints: Uberto Bortolotti, MD, Sezione di Cardiochirurgia, Dipartimento Cardiotoracico, Ospedale Cisanello, Via Paradisa 2, 56124, Pisa, Italy (E-mail: u.bortolotti@cardchir.med.unipi.it).

J Thorac Cardiovasc Surg 2003;126:1198-9

Copyright (C) 2003 by The American Association for Thoracic Surgery $0022-5223 / 2003 \$ 30.00+0$

doi:10.1016/S0022-5223(03)00368-4
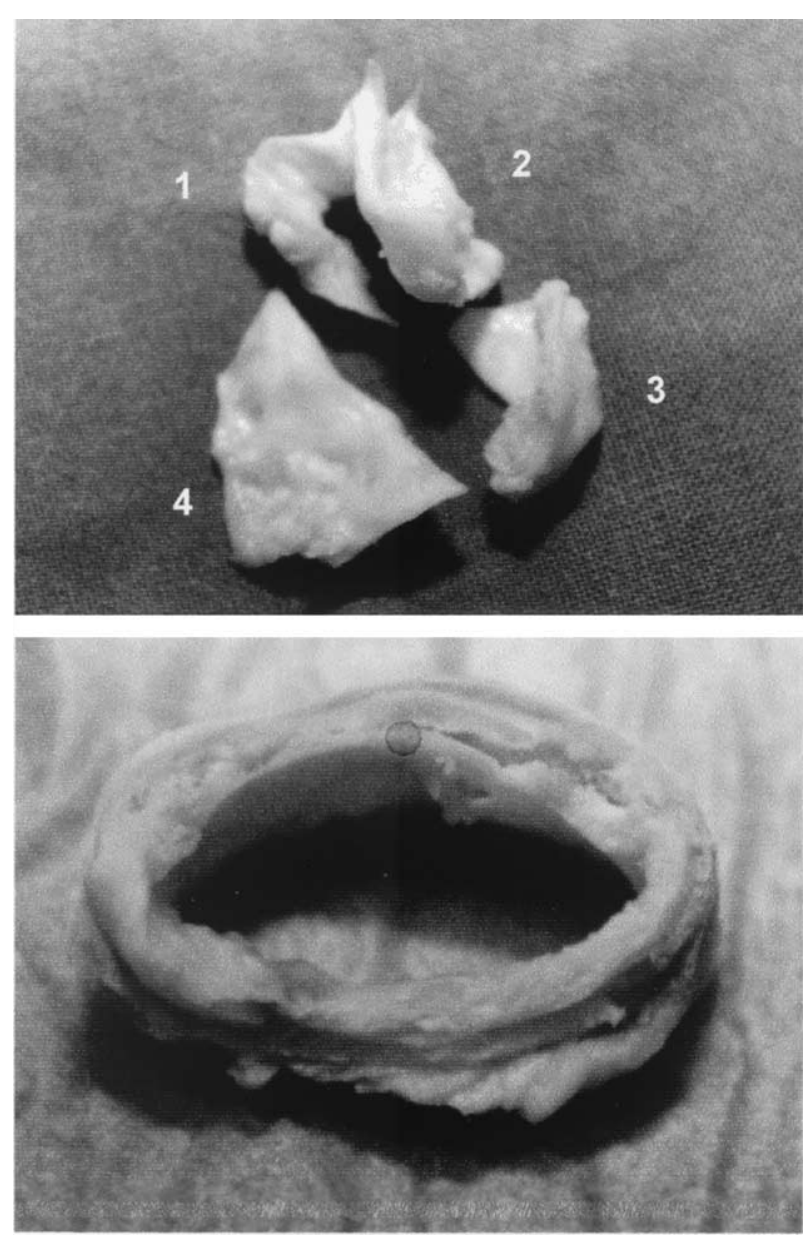

Figure 1. Gross view of the explanted valve (upper) showing 4 calcified cusps indicated by numbers. Gross view of a segment of ascending aorta (lower) with thickened and calcified wall.

to the donor aorta before release of the aortic crossclamp. The patient recovered uneventfully and was discharged on postoperative day 7.

\section{Discussion}

The adverse effects of mediastinal radiation therapy on the cardiovascular system are well documented. Pericardial disease is clinically evident in $60 \%$ to $70 \%$ of patients receiving mediastinal irradiation followed by valvular and coronary disease. ${ }^{4}$ In a postmortem series, Brosius and colleagues ${ }^{5}$ found that $80 \%$ of the patients studied showed evidence of valve damage after mediastinal irradiation. Veinot and Edwards ${ }^{6}$ reported a pathologic study of 27 patients exhibiting radiation-related cardiac injuries involving 
25 valves with various degrees of fibrosis and calcification. Surgical treatment of postradiation valvular disease has been reported, predominantly in patients with aortic stenosis. ${ }^{4}$ The largest surgical series for radiation-induced valvular heart disease was recently performed by Handa and associates. ${ }^{7}$ In this single-center retrospective study of 60 patients, they reported a $43 \%$ incidence of isolated aortic valve replacements.

Valvular incompetence is the most frequent hemodynamic abnormality in patients with a quadricuspid aortic valve. ${ }^{1-3}$ The occurrence of a severe aortic stenosis in the setting of a quadricuspid aortic valve is an exceptional finding and has not been reported. No such cases were recorded by Turri and colleagues ${ }^{8}$ among 140 aortic valve specimens retrieved at surgery for aortic stenosis, and Passik and colleagues ${ }^{9}$ did not mention any case of quadricuspid stenotic valve in 646 aortic valves explanted for pure stenosis. Our patient had severe aortic stenosis and coronary artery disease approximately 30 years after mediastinal irradiation for a metastatic seminoma. At operation, a calcified quadricuspid aortic valve was found characterized by a small accessory cusp between the right and noncoronary cusps which, according to Hurwitz and Roberts, ${ }^{1}$ is the most frequent variety of this malformation.

Quadricuspid aortic valves are prone to develop fibrosis, causing valve incompetence. ${ }^{3}$ In the present case, previous mediastinal irradiation is likely to have contributed to cusp calcification, allowing this malformation to develop an unusual pattern of valve dysfunction. Concomitant severe calcification of the ascending aorta and coronary artery disease indicate an extensive cardiac involvement from the effects of radiation.

\section{References}

1. Hurwitz LE, Roberts WC. Quadricuspid semilunar valves. Am J Cardiol. 1973;31:623-6.

2. Waller BF, Taliercio CP, Dickos DK, Howard J, Adlam JH, Jolly W. Rare or unusual causes of chronic, isolated, pure aortic regurgitation. Clin Cardiol. 1990;13:577-81.

3. Bortolotti U, Scioti G, Levantino M, Milano A, Nardi C, Tartarini G. Aortic valve replacement for quadricuspid aortic valve incompetence. J Heart Valve Dis. 1998;7:515-7.

4. Veeragandham RS, Golding MD. Surgical management of radiationinduced heart disease. Ann Thorac Surg. 1998;65:1014-9.

5. Brosius FC, Waller BF, Roberts WC. Analysis of 16 young (aged 15 to 33 years) necropsy patients who received over 3500 rads to the heart. Am J Med. 1981;70:519-30.

6. Veinot JP, Edwards WD. Pathology of radiation-induced heart disease: a surgical and autopsy study of 27 cases. Hum Pathol. 1996;27:766-73.

7. Handa N, McGregor CGA, Danielson GK, Daly RC, Dearani JA, Mullany CJ, et al. Valvular heart operation in patients with previous mediastinal radiation therapy. Ann Thorac Surg. 2001;71:1880-4.

8. Turri M, Thiene G, Bortolotti U, Milano A, Mazzucco A, Gallucci V. Surgical pathology of aortic valve disease. A study based on 602 specimens. Eur J Cardiothorac Surg. 1990;4:556-60.

9. Passik CS, Ackerman DM, Pluth JR, Edwards WD. Temporal changes in the causes of aortic stenosis: a surgical pathologic study of 646 cases. Mayo Clin Proc. 1987;62:119-23.

\title{
Chylous leak after cervical mediastinoscopy
}

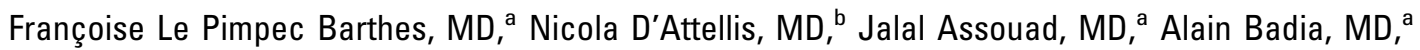 \\ Redha Souilamas, MD, and Marc Riquet, MD, PhD, ${ }^{a}$ Paris, France
}

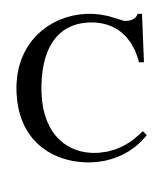

hylous leak after cervical mediastinoscopy is a rare complication. ${ }^{1}$ To our knowledge, 3 cases have been reported in the literature..$^{2-4}$ Three consecutive cases observed at our institution drew our attention to its possibly underrated occurrence.

\section{Clinical Summary}

PATIENT 1. A 16-year-old girl reported having weight loss and asthenia after an episode of erythema nodosum. On physical ex-

\footnotetext{
From Service de Chirurgie Thoracique ${ }^{\mathrm{a}}$ and Service d'Anesthésie Réanimation, ${ }^{\mathrm{b}}$ Hôpital Européen Georges Pompidou, Paris, France.

Received for publication Aug 29, 2002; accepted for publication Oct 22, 2002.

Address for reprints: Marc Riquet, MD, PhD, Service de Chirurgie Thoracique, Hôpital Européen Georges Pompidou, 20-40 rue Leblanc, 75015 Paris, France (E-mail: marc.riquet@hop.egp.ap-hop-paris.fr).

J Thorac Cardiovasc Surg 2003;126:1199-200

Copyright $\odot 2003$ by The American Association for Thoracic Surgery $0022-5223 / 2003 \$ 30.00+0$

doi:10.1016/S0022-5223(03)00799-2
}

amination, there was no lymphadenopathy or hepatomegaly. The chest radiograph demonstrated bulky paratracheal lymph nodes. Tuberculosis was suspected but could not be confirmed. Diagnosis was assessed by cervical mediastinoscopy, so as to rule out a lymphoma. During the procedure, active suction drainage of the mediastinal bed was used, yielding $300 \mathrm{~mL}$ of a milky fluid on postoperative day 1 . A chylous leak was confirmed by the presence of chylomicrons and triglycerides $(14.6 \mathrm{mmol} / \mathrm{L})$ in the fluid. Suction was discontinued, and a medium-chain triglyceride (MCT) diet was started. Lymphangiography demonstrated backflow of the contrast medium from the thoracic duct into the paratracheal lymph nodes (Figure 1). The chylous leak stopped, the mediastinum remained unchanged on successive chest radiographs, and the drain was removed on the fourth postoperative day.

PATIENT 2. A 56-year-old man had a superior vena caval obstruction syndrome. On physical examination, there was no lymphadenopathy or hepatomegaly. Chest tomodensitometry demonstrated a huge right lung tumor and large paratracheal lymph nodes. Fibrobronchoscopy failed to provide a diagnosis. A mediastinoscopy was performed. The mediastinal bed was not drained. The diagnosis of squamous cell carcinoma was confirmed. On postoperative day 3 , the mediastinoscopy incision leaked a milky 